\title{
Symptom evaluation of long-term postoperative outcomes after pylorus-preserving gastrectomy for early gastric cancer
}

\author{
Souya Nunobe, Mitsuru Sasako, Makoto Saka, Takeo Fukagawa, Hitosho Katai, and Takeshi Sano \\ Department of Surgery, National Cancer Center Hospital, Tokyo 104-0045, Japan
}

\begin{abstract}
Background. Since the early 1990s, pylorus-preserving gastrectomy (PPG) has been used in the treatment of patients with early gastric cancer in order to reduce postprandial symptoms. To date, there have been few reports of long-term symptom evaluation following this procedure. The aim of this study was to evaluate long-term postoperative outcomes after PPG.

Methods. Three hundred and ninety-seven patients with early gastric cancer were enrolled in this study: 194 patients who underwent PPG and 203 who underwent distal gastrectomy with Billroth-I reconstruction (DGBI). We compared the symptoms for the two groups in a questionnaire on postoperative functional outcomes, endoscopy findings and the appearance of gallstones after surgery.

Results. The incidence of symptoms suggesting early dumping syndrome was significantly lower in the PPG group compared with the DGBI group $(P<0.05)$. The incidences of disturbed bowel habit and frequent flatus were significantly lower in the PPG than in the DGBI group. The average relative body weight (actual BW/ BW immediately before the surgery) was significantly better in the PPG than in the DGBI group $(P<$ 0.001).

Conclusion. The long-term results show that PPG has clear advantages over DGBI in terms of postoperative symptoms and functional outcomes. These results imply that PPG should be the recommended procedure for early gastric cancers located in the middle third of the stomach.
\end{abstract}

Key words Pylorus-preserving gastrectomy · Postoperative evaluation · Dumping syndrome

Offprint requests to: M. Sasako

Department of Surgery, Hyogo College of Medicine, 1-1 Mukogawa-cho, Nishinomiya 663-8501, Japan

Received: June 6, 2007 / Accepted: July 30, 2007

\section{Introduction}

The incidence of early gastric cancer has been increasing for decades, reaching nearly $60 \%$ in Japan [1-4]. A conventional distal gastrectomy with lymph node dissection followed by Billroth-I -type reconstruction (DGBI) has been the accepted procedure for early gastric cancer in the middle third of the stomach [5]. While this treatment has achieved excellent survival, dumping syndrome, remnant gastritis, reflux esophagitis, and impaired weight gain are common in patients who have undergone DGBI [6].

The low probability of lymph node metastasis in these early tumors has allowed limited resections to be used increasingly [7]. However, the application of limited surgery without lymph node dissection leads to an increased likelihood of recurrence. As such, endoscopic submucosal dissection (ESD) is employed only after careful selection of $\mathrm{T} 1$ tumors whose probability of nodal metastasis is negligible [7-8].

In recent years, pylorus-preserving gastrectomy (PPG), known as the Maki operation [9], has been performed in patients with early gastric cancers located in the middle third of the stomach, in order to preserve the function of the pylorus as a physiologic regulator of gastric emptying and to prevent postprandial symptoms. Theoretically, because this procedure could be a good solution for postgastrectomy symptoms associated with conventional procedures, it is currently carried out in many Japanese hospitals.

Although several reports have evaluated outcomes following limited resection, the number of cases has been small, with too short an observation period to offer definitive evidence of the superiority of these procedures [10-19].

This study presents results for 194 patients who have undergone PPG and 203 patients who have undergone DGBI for early gastric cancer, with more than 3 years' postoperative data, including symptom scoring. 


\section{Patients and methods}

\section{Patients}

Clinical data were prospectively recorded according to The Japanese classification of gastric carcinoma [20]. We reviewed the case records of consecutive patients treated by the staff surgeons at the National Cancer Center Hospital between 1993 and 2000.

A total of 1291 patients with early gastric were treated, of whom 965 patients underwent PPG or distal gastrectomy; 380 patients underwent DGBI between 1993 and 1999 and 234 patients underwent PPG between 1995 and 2000. Between 1993 and 1999, the Billroth-I technique was gradually phased out and a Roux-en-Y reconstruction method was used after distal gastrectomy. DGBI is no longer used. The first PPG was carried out at our institute in 1995, and the number of patients undergoing this procedure has increased each year.

We identified 234 patients following PPG and 241 patients following DGBI who had undergone at least one endoscopy and abdominal ultrasonography within 3 years of surgery.

We excluded 20 patients who developed a second cancer, 2 who died of other causes, 4 who had developed or died from a gastric remnant cancer, and 8 whose surgery had been performed by surgeons who did not participate in this study. The gastric remnant cancers had developed in the remnant gastric body, not in the remnant pyloric cuff. Questionnaires identifying postoperative symptoms were sent to 212 patients following PPG and 229 following DGB1. Finally, 194 patients in the PPG group (mean age, 56.8 years) and 203 patients in the DGBI group (mean age, 58.7 years) with completed questionnaires were evaluated.

\section{Operative procedures}

$P P G$. The indication for PPG was early gastric cancer located in the middle third of the stomach. A pyloric cuff of $2.5 \mathrm{~cm}$ to $6.0 \mathrm{~cm}$ in length was retained. When the tumor was located in the lower to middle body of the stomach, the length of the remnant pyloric cuff was longer because of the smaller proximal remnant to make the total volume of the gastric remnant large enough. The hepatic and pyloric branches of the vagal nerve, and the right gastric vessels, were preserved up to the first branch to the stomach wall. The celiac branch of the vagal nerve and the infrapyloric artery and vein were also preserved in some patients, with complete dissection of the subpyloric lymph node and left gastric or celiac lymph nodes.
$D G B I$. All the patients underwent Kocher's maneuver to mobilize the duodenum, thereby minimizing the tension at the gastroduodenal anastomosis. All patients underwent a D1 $+\beta$ or D2 lymph node dissection.

\section{Methods of symptom evaluation}

Questionnaires to compare the two procedures were completed at two time points-in 2000 for those who underwent DGBI or PPG before 1997, and in 2004 for those who underwent PPG or DGBI between 1998 and 2000.

The questionnaire used in this study consisted of 37 questions for the patients to answer pertaining to gastrointestinal complaints and symptoms. The questionnaire asked about postoperative symptoms, including those corresponding to early dumping syndrome (within 30 min after meals; based on the diagnostic criteria for dumping syndrome established by the Japanese Society of Gastroenterological Surgery) [21], those related to late dumping syndrome ( 2 to $3 \mathrm{~h}$ after meals [cold sweat, dizziness, syncope, general malaise, tremor]), and those associated with disturbed gastric emptying between meals (abdominal distention, epigastric discomfort, continuous fullness, continuous nausea, rumbling, heartburn, hiccup, belching, continuous abdominal pain). Other questions, about meal volume, bowel movement, flatus, and overall satisfaction with the operation were included in the questionnaire (Table 1).

\section{Postoperative follow-up}

Postoperative follow-up included clinical and laboratory examinations every 6 months for the first 2 years and annually thereafter. Body weight was measured and any changes were recorded. Relative body weight (present/preoperative) was calculated in each subject. Endoscopy was performed and the findings graded as previously reported [22]. Grade B or worse esophagitis according to the Los Angeles classification was regarded as positive. Transabdominal ultrasound was performed as part of the routine follow-up.

\section{Statistical methods}

Statistical analyses were performed with SPSS statistical software (Chicago, IL, USA). Student's $t$-test and the $\chi^{2}$ test were used for comparisons between the two groups. Statistical significance was defined as $P<0.05$. 
Table 1. Questionnaire survey about postoperative symptoms established by the Japanese Society of Gastroenterological Surgery [21]

(1) Early dumping syndrome (symptoms within 30 min after a meal)

Systemic symptoms

1. Do you break into a cold sweat?

2. Do you have palpitations?

3. Do you have dizziness?

4. Do you feel numbness or lose consciousness?

5. Does your face look red?

6. Does your face look pale?

7. Do you feel hot over the whole body? Do you have a sensation of heat in the whole body?

8. Do you feel general malaise and weakness?

9. Do you suffer from drowsiness?

10. Do you have headaches or does your head feel heavy?

11. Do you have pain in your chest?

Abdominal symptoms

1. Does your stomach rumble?

2. Do you have a stomachache?

3. Do you have diarrhea?

4. Do you have nausea?

5. Do you suffer from vomiting?

6. Do you have abdominal distension?

7. Do you have abdominal discomfort?

(2) Late dumping syndrome (symptoms a couple of hours after a meal)

1. Do you have cold sweats?

2. Do you have dizziness?

3. Do you lose consciousness or have convulsions?

4. Do you feel general fatigue and/or languor?

5. Do you have finger tremor?

(3) Emptying disturbance (symptoms between meals)

1. Do you have early satiety?

2. Do you have a heavy feeling in your stomach?

3. Do you have nausea?

4. Do you belch excessively?

5. Do you have abdominal distension?

6. Do you have regurgitation?

7. Do you have heartburn?

8. Do you have hiccups?

9. Do you have epigastric pain?

(4) Others

1. Are you satisfied with your treatment so far?

2. Tell us about the size of your daily meals (including between-meal snacks).

3. Tell us about your present bowel habits (diarrhea and constipation).

4. Tell us about any changes in your bowel habit.

5. Do you have excessive flatus?

\section{Results}

\section{Patients and operative characteristics}

The patients in the two groups were equally matched (Table 2).

\section{Questionnaire}

The incidences of symptoms corresponding to early dumping syndrome, including dizziness, stomach rumbling, diarrhea, and vomiting were significantly lower in those who underwent PPG than in those who underwent DGBI $(P<0.05$; Table 3$)$. There were no significant differences in the incidence of symptoms of late dumping syndrome and symptoms associated with disturbance in gastric emptying between the PPG and DGBI groups (Tables 4, 5). The incidence of bowel disturbance was significantly higher in the DGBI group than in the PPG group, excessive flatus was significantly less common in the PPG than in the DGBI group. There was no significant difference between the two groups in average meal volume or in the proportion of those who felt satisfied or dissatisfied with the operation (Table $6)$.

\section{Change in body weight}

The relative body weights (present/preoperative) were $90.2 \pm 9.7 \%$ and $93.9 \pm 7.3 \%$ in the DGBI and PPG groups, respectively. The loss of body weight was significantly less in the PPG group than in the DGBI group $(P<0.0001$ by Student's $t$-test; Table 7$)$.

\section{Endoscopic findings}

Residual food in the remnant stomach was more frequently observed in the PPG group than in the DGBI group. There was no significant difference in other endoscopic findings between the groups (Table 8).

\section{Gallstones}

Gallstones appeared following gastrectomy in $10.8 \%$ of those who underwent PPG and in $13.3 \%$ of those who underwent DGBI. There was no significant difference between the groups (Table 9).

\section{Discussion}

Various reconstructive procedures, such as Billroth-I, Billroth-II, and jejunal pouches [23] have been used in an attempt to improve the symptoms for patients following distal gastrectomy. Billroth-I and -II reconstructions have been performed most commonly because of their simplicity. However, they often lead to duodenogastric reflux and gastritis and produce symptoms after distal gastrectomy that adversely affect the quality of life for these patients [24, 25]. The PPG procedure with vagal nerve preservation can be performed safely with a low incidence of major complications and a better 
Table 2. Characteristics of the two groups of patients who underwent pyloruspreserving gastrectomy (PPG) and distal gastrectomy reconstructed by the Billroth-I method (DGBI)

\begin{tabular}{lll}
\hline & \multicolumn{1}{c}{$\begin{array}{c}\text { PPG } \\
n=194\end{array}$} & \multicolumn{1}{c}{$\begin{array}{c}\text { DGBI } \\
n=203\end{array}$} \\
\hline Male:Female & $121: 73$ & $127: 76$ \\
Resection of stomach & $1 / 2-2 / 3$ & $2 / 3$ \\
Lymph node dissection & D2 - No. 5 & D1 $+\beta$ or D2 \\
Anastomosis & Gastro - gastro & Gastro - duodenum \\
Pylorus ring & Preserved & Absent \\
Food passage through & Yes & Yes \\
$\quad$ duodenum & 194 & 6 \\
Hepatic branch of vagus & 194 & 0 \\
Pyloric branch & 99 & 4 \\
Celiac branch & & \\
\hline
\end{tabular}

Table 3. Outcome of the questionnaire on symptoms suggestive of early dumping syndrome

\begin{tabular}{lrrr}
\hline Symptoms & $\begin{array}{c}\text { PPG } \\
n=194\end{array}$ & $\begin{array}{c}\text { DGBI } \\
n=203\end{array}$ & $P$ value \\
\hline Cold sweat & 1 & 2 & 0.589 \\
Palpitation & 2 & 4 & 0.443 \\
Dizziness & 0 & 8 & 0.005 \\
Numbness & 2 & 2 & 0.964 \\
Facial redness & 3 & 0 & 0.075 \\
Facial pallor & 1 & 1 & 0.974 \\
Heat & 4 & 1 & 0.161 \\
General malaise & 4 & 8 & 0.274 \\
Sleepiness & 8 & 10 & 0.701 \\
Headache & 1 & 6 & 0.065 \\
Chest pain & 3 & 5 & 0.516 \\
Rumbling & 7 & 26 & 0.001 \\
Abdominal pain & 3 & 10 & 0.059 \\
Diarrhea & 6 & 26 & 0.000 \\
Nausea & 2 & 8 & 0.064 \\
Vomiting & 0 & 5 & 0.028 \\
Abdominal fullness & 21 & 25 & 0.643 \\
Discomfort & 16 & 18 & 0.825 \\
\hline
\end{tabular}

Table 4. Outcome of the questionnaire on symptoms suggestive of late dumping syndrome

\begin{tabular}{lccc}
\hline Symptoms & $\begin{array}{c}\text { PPG } \\
n=194\end{array}$ & $\begin{array}{c}\text { DGBI } \\
n=203\end{array}$ & $P$ value \\
\hline Cold sweat & 1 & 2 & 0.166 \\
Dizziness & 2 & 1 & 0.328 \\
Syncope & 0 & 0 & 0.974 \\
General malaise & 2 & 9 & 0.316 \\
Tremor & 3 & 5 & 0.278 \\
\hline
\end{tabular}

Table 5. Outcome of the questionnaire on symptoms corresponding to gastric emptying disturbance after meals

\begin{tabular}{lrrr}
\hline Symptoms & $\begin{array}{c}\text { PPG } \\
n=194\end{array}$ & $\begin{array}{c}\text { DGBI } \\
n=203\end{array}$ & $P$ value \\
\hline Abdominal distension & 19 & 27 & 0.275 \\
Epigastric discomfort & 20 & 15 & 0.305 \\
Continuous fullness & 20 & 26 & 0.437 \\
Continuous nausea & 1 & 6 & 0.065 \\
Rumbling & 9 & 3 & 0.066 \\
Heartburn & 14 & 13 & 0.748 \\
Hiccup & 3 & 5 & 0.516 \\
Belching & 14 & 24 & 0.119 \\
Continuous & 5 & 3 & 0.436 \\
$\quad$ abdominal pain & & & \\
\hline
\end{tabular}

Table 6. Outcome of the questionnaire on other symptoms

\begin{tabular}{lrrr}
\hline Questions & $\begin{array}{c}\text { PPG } \\
n=194\end{array}$ & $\begin{array}{c}\text { DGBI } \\
n=203\end{array}$ & $P$ value \\
\hline $\begin{array}{l}\text { Intake volume }<50 \% \\
\quad \text { of preoperative value }\end{array}$ & 27 & 29 & 0.916 \\
$\begin{array}{l}\text { Bowel disturbance } \\
\text { Frequent flatus }\end{array}$ & 27 & 51 & 0.005 \\
$\begin{array}{l}\text { Overall dissatisfaction } \\
\quad \text { with operation }\end{array}$ & 94 & 137 & 0.000 \\
$\begin{array}{l}\text { Overall satisfaction } \\
\quad \text { with operation }\end{array}$ & 159 & 3 & 0.955 \\
\hline
\end{tabular}

Table 7. Body weight changes in the two groups of patients who underwent pylorus-preserving gastrectomy (PPG) and distal gastrectomy reconstructed by the Billroth-I method (DGBI)

\begin{tabular}{lcc}
\hline Relative body weight & PPG & DGBI \\
\hline Present/preoperative (\%) & $93.9 \pm 7.3$ & $90.2 \pm 9.7$ \\
\hline
\end{tabular}

DGBI vs PPG, $P<0.001$ 
Table 8. Endoscopic findings in the two groups of patients who underwent pylorus-preserving gastrectomy (PPG) and distal gastrectomy reconstructed by the Billroth-I method (DGBI)

\begin{tabular}{lccc}
\hline Findings & $\begin{array}{c}\text { PPG } \\
n=194\end{array}$ & $\begin{array}{c}\text { DGBI } \\
n=203\end{array}$ & $P$ value \\
\hline Esophagitis & 12 & 5 & 0.143 \\
$\begin{array}{l}\text { Gastritis of remnant } \\
\quad \text { stomach }\end{array}$ & 24 & 17 & 0.191 \\
Residual food & & & \\
Bile reflux & 42 & 27 & 0.028 \\
\hline
\end{tabular}

Table 9. Gallstone formation in the two groups of patients who underwent pylorus-preserving gastrectomy (PPG) and distal gastrectomy reconstructed by the Billroth-I method (DGBI)

\begin{tabular}{lcc}
\hline & Incidence & Percentage \\
\hline PPG & $21 / 194$ & 10.8 \\
DGBI & $27 / 203$ & 13.3 \\
\hline
\end{tabular}

DGBI vs PPG, $P=0.449$

postoperative outcome than the Billroth-type reconstructions $[2,6,26]$. However, long-term postoperative evaluation including symptom scoring has not been assessed in detail for large numbers of patients following PPG.

Most published studies on the functional outcome after PPG have been performed at 1 year postoperatively, with only two studies with late results following surgery $[18,19]$. Kodama et al. [10] reported that early morbidity did not differ between PPG and DGBI, and that the most frequent complication was gastric stasis after PPG. Similar findings were reported in another study [11-13].

Shibata et al. [19] reported long-term results including those for 36 patients after PPG, which revealed that the occurrence of early dumping syndrome was lower in the PPG group than in DGBI patients and that there was no difference between the two groups in body weight change, food intake, and overall satisfaction with the operation. Tomita et al. [18] also reported long-term results, including those for 10 patients 5-years after PPG without preservation of the vagal nerve. In their study, the only weakness of the PPG procedure was a sensation of epigastric fullness due to gastric stasis of food in the remnant stomach. They also reported that results showing post-gastrectomy syndrome after the PPG without nerve preservation were the same as those after the PPG with nerve preservation. The number of patients with long-term results after PPG in both these reports was too small to provide good postoperative symptom data following the PPG operation.
In the present study, nearly 200 patients were subject to long-term evaluation following PPG. Our study showed that the incidences of early dumping syndrome and postoperative body weight loss were significantly lower in the PPG than in the DGBI group. Contrary to previous studies, the incidence of gastric stasis with PPG was the same as that with DGBI [19]. In the longterm, it may be important to preserve the vagal nerve for improved gastric emptying.

It has been reported that patients undergoing DGBI without preservation of the hepatic and pyloric branches of the vagal nerve are at increased risk of developing cholecystolithiasis, with an incidence of $10 \%$ to $40 \%$ [10]. Nabae et al. [27] suggested that preservation of pyloroduodenal myoneural continuity during PPG would help maintain a normal sphincter of Oddi and gallbladder. The data in our study corroborate these previous reports $[10,27]$ in that the incidence of gallstones was lower in the PPG group. Almost all patients with DGBI in the present study underwent gastrectomy with vagal denervation.

In conclusion, the long-term results indicate that PPG has some advantages over DGBI in terms of postoperative symptoms, and that the incidence of gastric stasis is not problematic following PPG. These data suggest that PPG has an improved postoperative long-term outcome and should be the recommended procedure for early gastric cancer located in the middle third of the stomach.

Acknowledgments The authors thank Dr. Alan Li, Department of Surgery, Whiston Hospital, Prescot, Merseyside, UK, for reviewing this article. This research was supported in part by a Grant-in-Aid for the Second Term Comprehensive 10-Year Strategy for Cancer Control, from the Ministry of Health, Labour, and Welfare, Japan.

\section{References}

1. Moriwaki Y, Kunisaki C, Kobayashi S, Harada H, Imai S, Kido $\mathrm{Y}$, et al. Progressive improvement of prognosis for patients with gastric cancer (dynamic stage grouping) with increasing survival interval from initial staging: how much longer can a given survivor expect to live? Surgery 2003;133:135-40.

2. Kodera Y, Yamamura Y, Kanemitsu Y, Shimizu Y, Hirai T, Yasui $\mathrm{K}$, et al. Lymph node metastasis in cancer of the middle-third stomach: criteria for treatment with a pylorus-preserving gastrectomy. Surg Today 2001;31:196-203.

3. Higashi $\mathrm{H}$, Natsugoe S, Ishigami S, Uenosono Y, Matsumoto M, Nakajo A, et al. Distribution of lymph node metastasis including micrometastasis in gastric cancer with submucosal invasion. World J Surg 2003;27:455-9.

4. Maehara Y, Kakeji Y, Oda S, Takahashi I, Akazawa K, Sugimachi K. Time trends of surgical treatment and the prognosis for Japanese patients with gastric cancer. Br J Cancer 2000;83: 986-91. 
5. Adachi Y, Shiraishi N, Shiromizu A, Bandoh T, Aramaki M, Kitano S. Laparoscopy-assisted Billroth I gastrectomy compared with conventional open gastrectomy. Arch Surg 2000;135: 806-10.

6. Osugi H, Fukuhara K, Takada N, Takemura H, Kinoshita H. Reconstructive procedure after distal gastrectomy to prevent remnant gastritis. Hepatogastroenterology 2004;51:1215-8.

7. Gotoda T, Yanagisawa A, Sasako M, Ono H, Nakanishi Y, Shimoda $\mathrm{T}$, et al. Incidence of lymph node metastasis from early gastric cancer: estimation with a large number of cases at two large centers. Gastric Cancer 2000;3:219-25.

8. Soetikno RM, Gotoda T, Nakanishi Y, Soehendra N. Endoscopic mucosal resection. Gastrointest Endosc 2003;57:567-79.

9. Maki T, Shiratori T, Hatafuku T, Sugawara K. Pylorus-preserving gastrectomy as an improved operation for gastric ulcer. Surgery 1967:61:838-42.

10. Kodama M, Koyama K, Chida T, Arakawa A, Gennady T. Early postoperative evaluation of pylorus-preserving gastrectomy for gastric cancer. World J Surg 1995;19:456-61.

11. Nakae Y, Akehira K, Inoue K, Iiyama H, Sato M, Masuya Y, et al. Postoperative evaluation of pylorus-preserving gastrectomy for early gastric cancer. Hepatogastroenterology 2000;47: $590-5$.

12. Imada T, Rino Y, Takahashi M, Suzuki M, Tanaka J, Shiozawa $M$, et al. Postoperative functional evaluation of pyloruspreserving gastrectomy for early gastric cancer compared with conventional distal gastrectomy. Surgery 1998;123:165-70.

13. Yamaguchi T, Ichikawa D, Kurioka H, Ikoma H, Koike H, Otsuji $\mathrm{E}$, et al. Postoperative clinical evaluation following pyloruspreserving gastrectomy. Hepatogastroenterology 2004;51:883-6.

14. Nishikawa K, Kawahara H, Yumiba T, Nishida T, Inoue Y, Ito $\mathrm{T}$, et al. Functional characteristics of the pylorus in patients undergoing pylorus-preserving gastrectomy for early gastric cancer. Surgery 2002;131:613-24.

15. Sawai K, Takahashi T, Fujioka T, Minato H, Taniguchi H, Yamaguchi T. Pylorus-preserving gastrectomy with radical lymph node dissection based on anatomical variations of the infrapyloric artery. Am J Surg 1995;170:285-8.

16. Isozaki H, Okajima K, Momura E, Ichinona T, Fujii K, Izumi N, et al. Postoperative evaluation of pylorus-preserving gastrectomy for early gastric cancer. Br J Surg 1996;83:266-9.
17. Hotta T, Taniguchi K, Kobayashi Y, Johata K, Sahara M, Naka $\mathrm{T}$, et al. Postoperative evaluation of pylorus-preserving procedures compared with conventional distal gastrectomy for early gastric cancer. Surg Today 2001;31:774-9.

18. Tomita R, Fujisaki S, Tanjoh K. Pathophysiological studies on the relationship between postgastrectomy syndrome and gastric emptying function at 5 years after pylorus-preserving distal gastrectomy for early gastric cancer. World J Surg 2003;27: 725-33.

19. Shibata C, Shiiba K, Funayama Y, Ishii S, Fukushima K, Mizoi $\mathrm{T}$, et al. Outcomes after pylorus-preserving gastrectomy for early gastric cancer: a prospective multicenter trial. World J Surg 2004; 28:857-61.

20. Japanese Gastric Cancer Association. Japanese classification of gastric carcinoma. Second English edition. Gastric Cancer 1998;1: $10-24$.

21. Nagao F, Hayashi S, Yamaguchi Y, Shiratori T, Ohkubo T, Okajima K, et al. Symposium "Early dumping syndrome". Jpn J Gastroenterol Surg 1972;4:1-20.

22. Kubo M, Sasako M, Gotoda T, Ono H, Fujishiro M, Saito D, et al. Endoscopic evaluation of the remnant stomach after gastrectomy: proposal for a new classification. Gastric Cancer 2002;5: 83-9.

23. Matsumoto K, Uchida Y, Noguchi T, Hashimoto T, Hiraoka Y, Kubo N. A device in reconstruction method after distal gastrectomy: special reference to double tract method with jejunal pouch. J Jpn Surg Soc. 1997;98:565-70.

24. Kim BJ, O'Connell T. Gastroduodenostomy after gastric resection for cancer. Am Surg 1999;65:905-7.

25. Svensson JO. Duodenogastric reflux after gastric surgery. Scand J Gastroenterol 1983;18:729-34

26. Fukuhara K, Osugi H, Takada N, Takemura M, Higashino M, Kinoshita H. Reconstructive procedure after distal gastrectomy for gastric cancer that best prevents duodenogastroesophageal reflux. World J Surg 2002;26:1452-7.

27. Nabae T, Takahashi S, Konomi H, Deng ZL, Yokohata K, Chijiiwa $\mathrm{K}$, et al. Effect of prepyloric gastric transection and anastomosis on sphincter of Oddi cyclic motility in conscious dogs. J Gastroenterol 2001;36:530-7. 